\title{
Regulation of HRG-ß1-induced proliferation, migration and invasion of MCF-7 cells by upregulation of GPR30 expression
}

\author{
SHU-QIN RUAN, SHAN-WEI WANG, ZHAN-HUAI WANG and SU-ZHAN ZHANG \\ Cancer Institute (Key Laboratory of Cancer Prevention and Intervention, China National Ministry of Education, \\ Key Laboratory of Molecular Biology in Medical Sciences, Zhejiang Province, China), The Second Affiliated Hospital, \\ School of Medicine, Zhejiang University, Hangzhou, Zhejiang 310009, P.R. China
}

Received January 10, 2012; Accepted April 2, 2012

DOI: $10.3892 / \mathrm{mmr} .2012 .874$

\begin{abstract}
The cooperation and communication between different cell signaling transduction pathways are considered critical in the development of various types of cancer as well as drug resistance. There is evidence of crosstalk between the G protein-coupled receptor 30 (GPR30), the newly discovered estrogen receptor (ER), and the ErbB family. Heregulin (HRG)- 31 , the ligand for ErbB3 and ErbB4, upregulates GPR30 expression in MCF-7, T-47D and BT-474 breast cancer cell lines that express ER $\alpha$. In the present study, recombinant human HRG- $\beta 1$ was used to investigate the upregulation of GPR30 expression by HRGs in MCF-7 breast cancer cells which were ER $\alpha$-positive. In MCF-7 cells, the ErbB2 inhibitor, AG825, the MAPK inhibitor, PD98059, and the MEK1/2 inhibitor, U0126, blocked the HRG- $\beta 1$-induced GPR30 expression. 17- $\beta$-estradiol (E2) boosted the HRG- $\beta 1$-induced proliferation, migration and invasion of MCF-7 cells. Similar to E2, the specific GPR30 agonist, G-1, promoted HRG- $\beta 1$ induced migration and invasion, but inhibited growth. Using the specific GPR30 antagonist, G-15, or the small interfering RNA for GPR30, the functions of GPR30 after treatment with HRG- $\beta 1$ were further investegated. The results from our study indicate that the interruption between GPR30 signaling and the ErbB family system may serve as a promising therapeutic strategy for breast cancer.
\end{abstract}

Correspondence to: Dr Su-Zhan Zhang, Cancer Institute, The Second Affiliated Hospital, School of Medicine, Zhejiang University, No. 88 Jiefang Road, Hangzhou, Zhejiang 310009, P.R. China E-mail: suzhanzhang@gmail.com

Abbreviations: HRG, heregulin; GPR30, G protein-coupled receptor 30; ER, estrogen receptor; siGPR30, small interfering RNA for GPR30; TAM, tamoxifen; GPCRs, G protein-coupled receptors; E2, 17- $\beta$-estradiol; MMP, matrix metalloproteinase; FBS, fetal bovine serum; HRP, horseradish peroxidase; CTGF, connective tissue growth factor; FN, fibronectin; CXCR4, chemokine receptor type 4

Key words: G protein-coupled receptor 30, heregulin, proliferation, migration, invasion, breast cancer

\section{Introduction}

The application of long-term anti-hormonal therapy for estrogen receptor $\alpha(E R \alpha)$-positive breast cancer benefits the prognosis of patients (1), and has become the standard treatment plan for breast cancer. Nevertheless, the majority of patients relapse with the eventual development of drug resistance, even after having received anti-hormonal therapy. Therefore, endocrine therapy resistance is one of the main challenges in the treatment of ER $\alpha$-positive breast cancer.

Over the past decade, it has become evident that the communication and cooperation among different signaling networks is critical in the regulation of diverse cellular functions, such as proliferation, differentiation, apoptosis, migration and survival. A number of studies have provided evidence of the existence of crosstalk between ER and growth factor receptor signaling pathways, particularly the ErbB family, which contributes to endocrine therapy resistance in breast cancer (2-4).

The G protein-coupled receptor 30 (GPR30), as a seventransmembrane domain receptor, belongs to the $\mathrm{G}$ proteincoupled receptors (GPCRs) that represent the largest family of membrane receptors. In 2004 and 2005, two studies reported that $17-\beta$-estradiol (E2) binds to and signals through GPR30 with high affinity and in vitro potency, respectively $(5,6)$. GPR30 has been speculated to have a potentially important role in cancer progression, including breast, endometrial, prostate, ovarian and thyroid cancers (7-12). A previous study, using a breast cancer patient specimen and cell model, showed that GPR30 signaling is involved in the development of endocrine therapy resistance $(13,14)$. Notably, the ER antagonists found in breast tissue, tamoxifen (TAM) and ICI 182780, act as GPR30 agonists $(15,16)$.

Neuregulins (NRGs; also known as heregulins, neu differentiation factor, acetylcholine receptor-inducing activity and glial growth factor) are a family of ligands for ErbB3 and ErbB4, which consists of NRG1 or heregulin (HRG), NRG2, NRG3 and NRG4. The binding of HRGs to the extracellular domain of the receptor tyrosine kinases, ErbB3 and ErbB4, leads to the formation of ErbB homo- or heterodimers, which in turn activates intracellular signaling pathways and drives cell proliferation, adhesion, differentiation and migration (17). In breast cancer, it has been reported that HRGs contribute to 
the acquisition of anti-hormonal drug resistance characteristic $(18,19)$ and distant metastasis $(20-22)$.

GPR30, as a member of GPCRs, transactivates epidermal growth factor receptor (EGFR) and its downstream signaling $(15,23)$. In turn, the epidermal growth factor (EGF) and transforming growth factor- $\alpha(\mathrm{TGF}-\alpha)$ upregulate GPR30 expression in certain ER $\alpha$-negative and ER $\alpha$-positive cancer cells, which enhances the proliferative effects of estrogen $(11,12)$. However, little is known about the correlation between GPR30 and HRGs. In the present study, recombinant human HRG- $\beta 1$ was used to investigate the upregulation of GPR30 expression by HRGs in MCF-7 breast cancer cells which were ER $\alpha$-positive. We show that elevated GPR30 expression is involved in the proliferation, migration and invasion induced by HRG- $\beta 1$. Our findings may facilitate future studies on the mechanism of endocrine therapy resistance.

\section{Materials and methods}

Cell culture and reagents. MCF-7, T-47D and BT-474 breast cancer cell lines were maintained in MEM, DMEM and RPMI1640 medium (Gibco, Carlsbad, CA, USA), respectively. All of the growth mediums were supplemented with $10 \%$ fetal bovine serum (FBS; Gibco).

The following reagents were solubilized as stock according to the manufacturer's recommendations: Recombinant human HRG- $\beta 1$ was obtained from PeproTech (Rocky Hill, NJ, USA), E2 and AG825 were from Sigma-Aldrich (St. Louis, MO, USA), AG1478, LY294002, U0126 and PD98059 were from Cell Signaling Technology (Danvers, MA, USA), G-1 was from Merck (Darmstadt, Germany) and G-15 was from Tocris Bioscience (Bristol, UK). Before use, stock solutions were diluted with phenol red-free growth medium. The final DMSO concentration was $<0.1 \%$ and had no effect on the parameters analyzed.

Western blot analysis. Cells were lysed in M-PER mammalian protein extraction reagent (Thermo Scientific, Barrington, IL, USA) with $1 \%$ protease inhibitors cocktail (Sigma-Aldrich). Protein concentration was determined using the bicinchoninic acid protein assay kit (Thermo Scientific). Equal amounts of whole protein samples from the total cell lysates were separated using a $10 \%$ sodium dodecyl sulfate-polyacrylamide gel electrophoresis gel and were then transferred to polyvinylidene fluoride membranes (Millipore, Billerica, MA, USA). The blots were incubated overnight at $4^{\circ} \mathrm{C}$ with primary antibodies. The membranes were washed three times with Tris-buffered saline with Tween-20 and then incubated for $1 \mathrm{~h}$ with horseradish peroxidase (HRP)-conjugated secondary antibodies at room temperature. Immunoreactive bands were visualized using the EZ-ECL chemiluminescence detection kit for HRP (Bioind, Kibbutz Beit Haemek, Israel). The following monoclonal (m) and polyclonal (p) antibodies (Ab) were used: anti GPR30 pAb (GeneTex, San Antonio, TX, USA); anti- $\alpha$-tublin mAb (Beyotime, Haimen, China).

Real-time quantitative polymerase chain reaction. Total cellular RNA in MCF-7 cells was isolated using TRIzol reagent (Invitrogen, Carlsbad, CA, USA) and treated with DNase I (Promega, Madison, WI, USA) to eliminate contaminated genomic DNA. Real-time reverse transcription PCR (RT-PCR) was performed using the PrimeScript RT reagent kit and SYBR Premix ExTaq (Takara, Shiga, Japan) following the manufacturer's instructions. PCR amplification was conducted in a StepOnePlus Real-Time PCR system (Applied Biosystems, Foster City, CA, USA) following the manufacturer's instructions. Relative quantification was defined using the $2^{-\Delta \Delta \mathrm{Ct}}$ method. The amount of GPR30 mRNA was normalized to the internal control GAPDH. The primers used were: 5'-GGTGCCAGGAC AATGAAATACTC-3' (GPR30 forward) and 5'-GATCCGCA CATGACAGGTTTATTG-3' (GPR30 reverse); 5'-GAAGGTG AAGGTCGGAGTCAAC-3' (GAPDH forward) and 5'-CCT GGAAGATGGTGATGGGATT-3' (GAPDH reverse).

Small interfering RNA (siRNA) transfection. MCF-7 cells were transiently transfected with the human GPR30 siRNA (siGPR30) or non-specific pre-synthesized control siRNA using Lipofectamine 2000 reagent (Invitrogen), following the manufacturer's instructions. These were used to interfere with GPR30 expression. The sequences of GPR30 siRNA were 5'-GCUGUACAUUGAGCAGAAATT-3' (sense) and 5'-UUU CUGCUCAAUGUACAGCTT-3' (antisense (GenePharma, China). All transfections were conducted in 6-well plates.

Cell proliferation assay. MCF-7 cells were grown in 24-well plates in complete medium for $24 \mathrm{~h}$ and then switched to phenol red-free medium with $2 \%$ charcoal-stripped FBS and the indicated treatments, which were renewed every two days. After treatment for three days, cells were harvested by trypsinization and the cell number was determined using a hemocytometer.

Migration and invasion assays. MCF-7 cells were serumstarved for $24 \mathrm{~h}$, and then incubated with the indicated treatments for $24 \mathrm{~h}$ in phenol red and serum-free medium. Subsequently, cells were trypsinized, washed and resuspended in phenol red-free MEM with $1 \%$ BSA. A total of $1 \times 10^{5}$ cells in $200 \mu \mathrm{l} \mathrm{MEM} /$ well with indicated reagents were loaded onto the upper compartments of Boyden chambers (Costar, Corning, NY, USA) and allowed to migrate in the presence of $400 \mu \mathrm{l}$ of MEM containing 10\% FBS which had been added to the lower compartments prior to the experiment. After incubation at $37^{\circ} \mathrm{C}$ for $48 \mathrm{~h}$, the migratory cells attached to the bottom surface of the membrane were stained with $0.1 \%$ crystal for $30 \mathrm{~min}$ at room temperature and counted.

The invasion experiments were performed with the chambers coated with $40 \mu 1$ Matrigel (BD Biosciences, Bedford, MA, USA), which had been diluted in serum-free medium at the ratio of: matrigel:medium, 1:3. Cells were allowed to invade through the Matrigel membrane for $48 \mathrm{~h}$. The other operations were the same as in the above-mentioned migration experiments.

Statistical analysis. Data were expressed as the means \pm SD. Statistical differences were evaluated by ANOVA followed by Newman-Keuls test. $\mathrm{P}<0.05$ denoted a statistically significant difference.

\section{Results}

HRG- $\beta 1$ upregulates GPR30 expression in MCF-7 cells. In ER-positive cancer cells, the EGFR ligands, EGF and TGF- $\alpha$, 
A

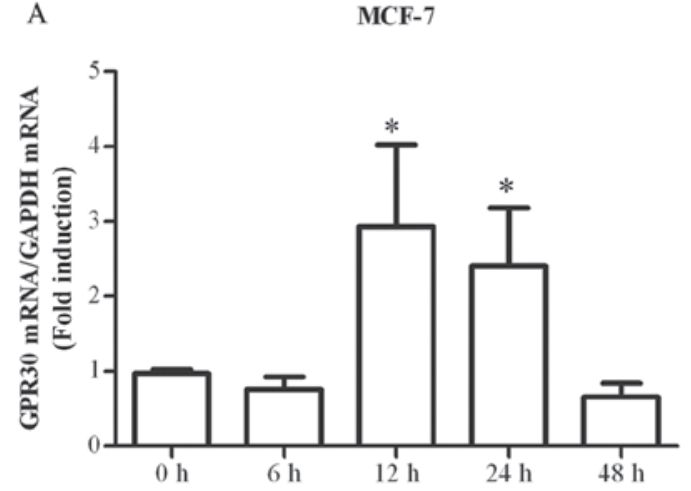

B
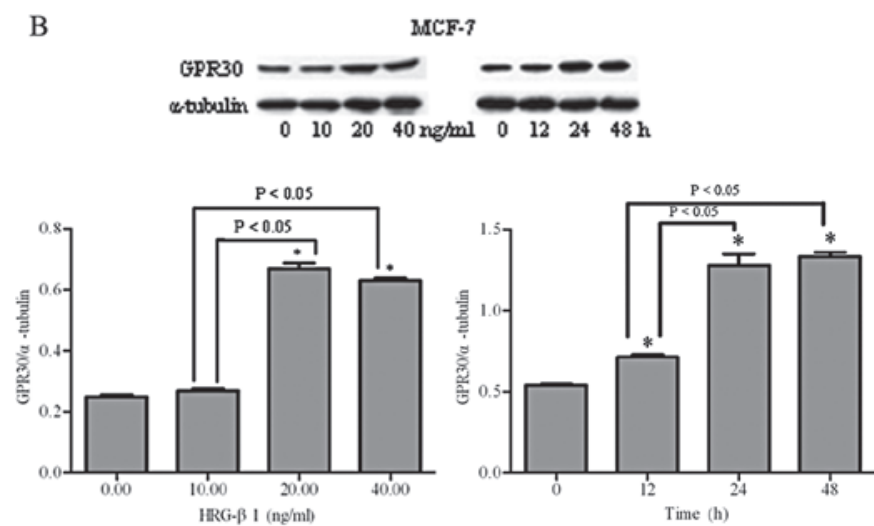

$\mathrm{C}$
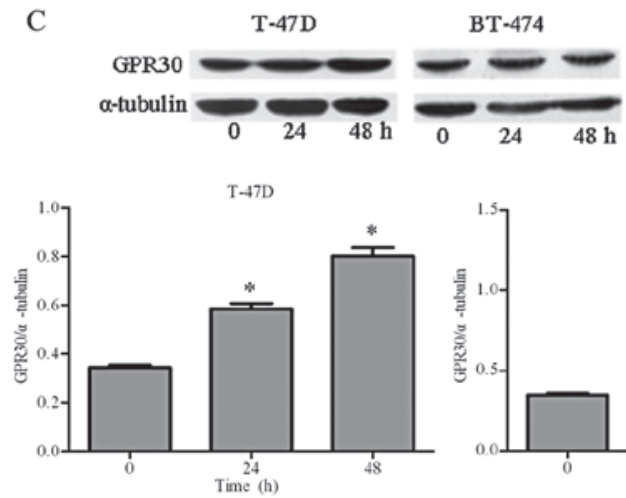

BT. 474

Figure 1. Heregulin (HRG)- $\beta 1$ upregulates $G$ protein-coupled receptor 30 (GPR30) expression in MCF-7 cells. (A) After treatment with $20 \mathrm{ng} / \mathrm{ml}$ HRG- $\beta 1$ for various periods of time, GPR30 mRNA levels in MCF-7 cells were detected by real-time PCR. The error bars are expressed as the means \pm SD of three independent experiments. GPR30 expression was normalized to that of GAPDH. ${ }^{*} \mathrm{P}<0.05$, for cells that received treatment for different times vs. $0 \mathrm{~h}$. (B) After treatment with various concentrations of HRG- $\beta 1$ for $24 \mathrm{~h}$ or with $20 \mathrm{ng} / \mathrm{ml}$ HRG- $\beta 1$ for different periods of time, GPR30 protein expression in MCF-7 cells was evaluated by western blot analysis. $\alpha$-tubulin served as the loading control. Data shown are representative of three independent experiments. The error bars are expressed as the means $\pm \mathrm{SD}$ of three independent experiments. ${ }^{*} \mathrm{P}<0.05$, for cells that received treatment vs. the control group. (C) After treatment with $20 \mathrm{ng} / \mathrm{ml}$ HRG- $\beta 1$ for 0, 24 and $48 \mathrm{~h}$, GPR30 protein expression in T-47D and BT-474 cells was examined by western blot analysis. $\alpha$-tubulin served as the loading control. Data shown are representative of three independent experiments. The error bars are expressed as the means $\pm \mathrm{SD}$ of three independent experiments. ${ }^{*} \mathrm{P}<0.05$, for cells that received treatment for different times vs. $0 \mathrm{~h}$.

have been shown to upregulate GPR30 expression in Ishikawa endometrial cancer cells and TAM-resistant MCF-7 breast cancer cells $(11,12)$. HRGs, as ligands for ErbB3 and ErbB4, possibly have the similar ability to regulate GPR30 expression in breast cancer. In our study, a time course investigation in MCF-7 cells following HRG- $\beta 1$ treatment was performed by real-time quantitative RT-PCR at first. As shown in Fig. 1A, the GPR30 mRNA expression increased after treatment with $20 \mathrm{ng} / \mathrm{ml} \mathrm{HRG}-\beta 1$ for $12 \mathrm{~h}$ and persisted for more than $24 \mathrm{~h}$. Then, with HRG- $\beta 1$ being depleted, GPR30 mRNA decreased, even lower than the untreated cells. Next, GPR30 protein levels were examined after treatment with various concentrations of HRG- $\beta 1$ for different periods of time. GPR30 protein levels were elevated in a time- and concentration-dependent manner. After 24 h of treatment, GPR30 protein levels significantly increased; this increase in protein levels occurred at a later stage compared to the increase in mRNA levels (Fig. 1B). We observed that GPR30 protein also increased in both T-47D and BT-474 breast cancer cell lines which expressed ER $\alpha$ and basic levels of GPR30 (Fig. 1C). Therefore, HRG- $\beta 1$ has the ability to upregulate GPR30 expression in ER $\alpha$-positive breast cancer cells.

Upregulation of GPR30 expression by HRG- $\beta 1$ is mainly associated with the activation of ErbB2-ERK signaling transduction pathway in MCF-7 cells. It has been established that ErbB3 and ErbB4 prefer to heterodimerize with ErbB2 when binding to HRG- $\beta 1$, which leads to receptor tyrosine phosphorylation and activates downstream signaling transduction primarily, including the MAPK/ERK and PI3K/ Akt pathways (24). Considering the upregulation of GPR30 expression by EGF and TGF- $\alpha$ through the EGFR-ERK transduction pathway $(11,12)$, we hypothesized that HRG- $\beta 1$ may increase GPR30 expression through the ErbB2-ERK signaling system. Therefore, specific pharmaceutical inhibitors were used to elucidate the signaling pathway connected with the regulation of GPR30 expression. As expected, the ErbB2 inhibitor, AG825, the MAPK inhibitor, PD98059, and the MEK1/2 inhibitor, U0126, inhibited the HRG- $\beta 1$-induced GPR30 expression, whereas the EGFR inhibitor, AG1478, and the PI3K inhibitor, LY294002, did not exhibit any inhibitory effect (Fig. 2B). These results indicate that HRG- $\beta 1$ mediates GPR30 expression primarily through the ErbB2-ERK signal transduction pathway.

GPR30 plays an inhibitory role in the proliferative effect induced by HRG- $\beta 1$ in MCF-7 cells. E2 is not only the ligand for ER, but is also the agonist for GPR30 (16). In our study, the proliferative effects in MCF-7 cells induced by E2, HRG- $\beta 1$ alone or in combination, were further promoted by the specific GPR30 antagonist, G-15 (Fig. 3A). Likewise, G-15 boosted the growth of MCF-7 cells when they were treated with the specific GPR30 agonist, G-1, HRG- $\beta 1$ alone or the combination of both, although G-1 itself inhibited MCF-7 cell proliferation (Fig. 3C). These results were further confirmed after GPR30 knockout using siGPR30 (Fig. 3B and D). Previous studies have shown that the upregulation of GPR30 by EGF engages E2 to boost the proliferation of ER $\alpha$-negative breast cancer cells and ER $\alpha$-positive Ishikawa endometrial cancer cells $(11,12)$. However, GPR30 has been shown to have a growth inhibitory effect on certain cell types (25-29). Our findings were consistent with those from other reports demonstrating that the activation of GPR30 signaling inhibits MCF-7 cell growth $(26,29)$. 

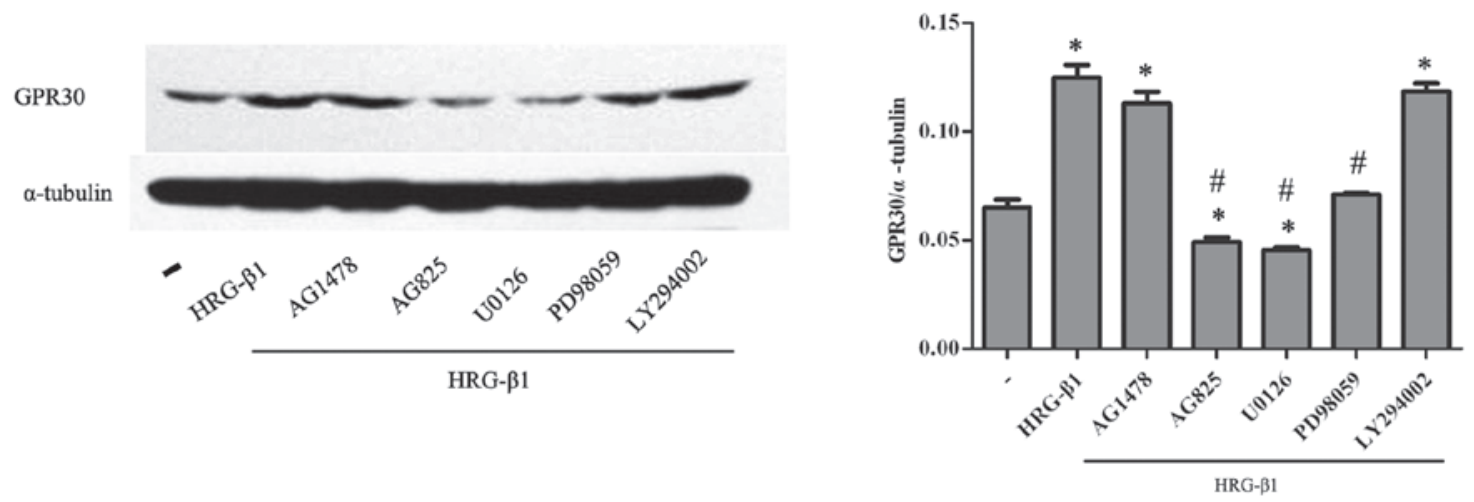

Figure 2. Heregulin (HRG)- $\beta 1$ induces G protein-coupled receptor 30 (GPR30) expression in MCF-7 cells primarily through the ErbB2-ERK signaling transduction pathway. Cells were treated with $20 \mathrm{ng} / \mathrm{ml}$ of HRG- $\beta 1$ alone or in combination with the EGFR inhibitor, tyrphostin AG1478 (10 $\mu \mathrm{M})$, the ErbB2 inhibitor, tyrphostin AG825 $(10 \mu \mathrm{M})$, the MAPK inhibitor, PD98059 (10 $\mu \mathrm{M})$, the MEK1/2 inhibitor, U0126 (10 $\mu \mathrm{M})$, and the PI3K inhibitor, LY294002 (10 $\mu \mathrm{M})$ for $24 \mathrm{~h}$. All inhibitors were pre-treated for $1 \mathrm{~h}$. GPR30 expression was examined using immunoblot analysis. $\alpha$-tubulin served as the loading control. Data represent three independent experiments. The error bars are expressed as the means $\pm \mathrm{SD}$ of three independent experiments. ${ }^{*} \mathrm{P}<0.05$, for cells that received treatment vs. vehicle (-).
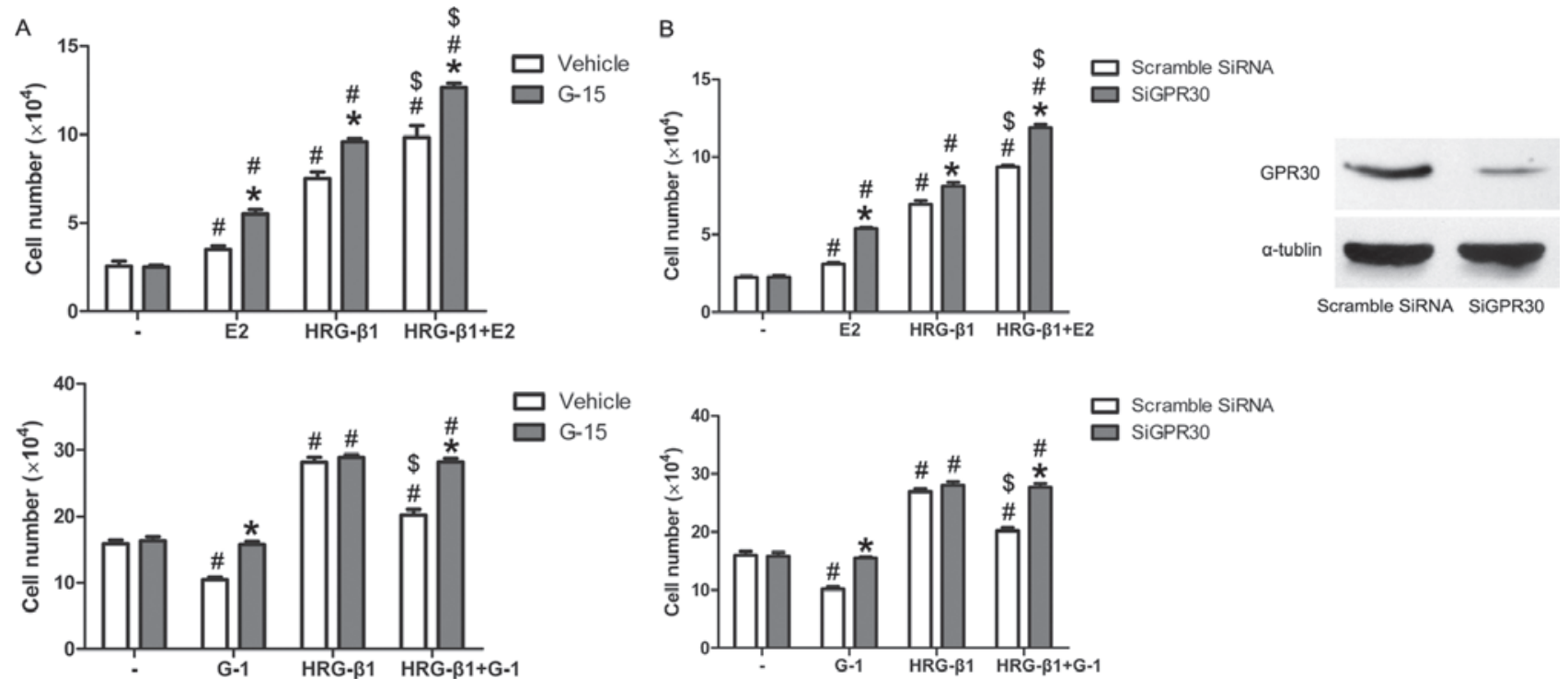

Figure 3. G protein-coupled receptor 30 (GPR30) upregulation inhibits the proliferative effects induced by heregulin (HRG)- $\beta 1$ in MCF-7 cells. On the first day, $1 \times 10^{4}$ [17- $\beta$-estradiol (E2) group] or 3x104 (G-1 group) cells per well were loaded into 24 -well plates. Then, cells were incubated with medium containing $2 \%$ charcoal-stripped FBS and the indicated reagents. Each data point is the mean \pm SD of three independent experiments performed in triplicate. (A and B) Growth effects influenced by $10 \mathrm{nM}$ E2 alone or in combination with $20 \mathrm{ng} / \mathrm{ml}$ HRG- $\beta 1$ were boosted by $1 \mu \mathrm{M} \mathrm{G}-15$ or GPR30 silencing siRNA (siGPR30). (C and D) Growth effects influenced by $1 \mu \mathrm{M} \mathrm{G}-1$ alone or in combination with $20 \mathrm{ng} / \mathrm{ml}$ HRG- $\beta 1$ were boosted by $1 \mu \mathrm{M}$ G-15 or GPR30 silencing siRNA (siGPR30). ${ }^{\text {"P}} \mathrm{P}<0.05$, for cells that received vehicle vs. G-15, or for cells that were transfected with scrambled siRNA vs. siGPR $30 .{ }^{*} \mathrm{P}<0.05$, for cells that received E2 (or G-1) and HRG- $\beta 1$ alone or a combination of E2 (or G-1) and HRG- $\beta 1$ vs. vehicle (-). ${ }^{\$} \mathrm{P}<0.05$, for cells that received HRG- $\beta 1$ alone or in combination with E2 (or G-1).

Elevation of GPR30 promotes the migration and invasion induced by HRG- $\beta 1$ in MCF-7 cells. Since GPR 30 and HRG- $\beta 1$ signaling has been reported to play a role in tumor metastasis $(8,22,30-32)$, we investigated whether GPR30 plays a role in the migration and invasion induced by HRG- $\beta 1$. The migration of MCF-7 cells was analyzed with a Boyden chamber migration assay. In this experiment, the number of cells that had migrated or invaded through the polycarbonate filter during the 48-h treatment period were counted. Indeed, E2, G-1 and HRG- $\beta 1$ alone had the ability to stimulate the migration and invasion of MCF-7 cells. With the combination treatment of E2 (or G-1) and HRG- $\beta 1$, the migration ability (Fig. $4 \mathrm{~A}$ and $\mathrm{C}$ ) and invasion (Fig. 4E and G) were enhanced, which were inhibited after the addition of G-15. Finally, we further confirmed this result using siGPR30. The knockdown of GPR30 also reduced the migration and invasion induced by HRG- $\beta 1$ in MCF-7 cells (Fig. 4B and D). These results support our hypothesis that GPR30 boosts the HRG- $\beta 1$-induced migration and invasion of MCF-7 cells.

\section{Discussion}

Increasing evidence has demonstrated that the crosstalk between the ErbB family and GPCRs generates a complex signaling network, which plays an important role in cancer progression (33-39). A number of studies have addressed the transactivation of ErbB family members, especially EGFR, due to the activation of GPCRs signaling $(37,40,41)$. Positive 

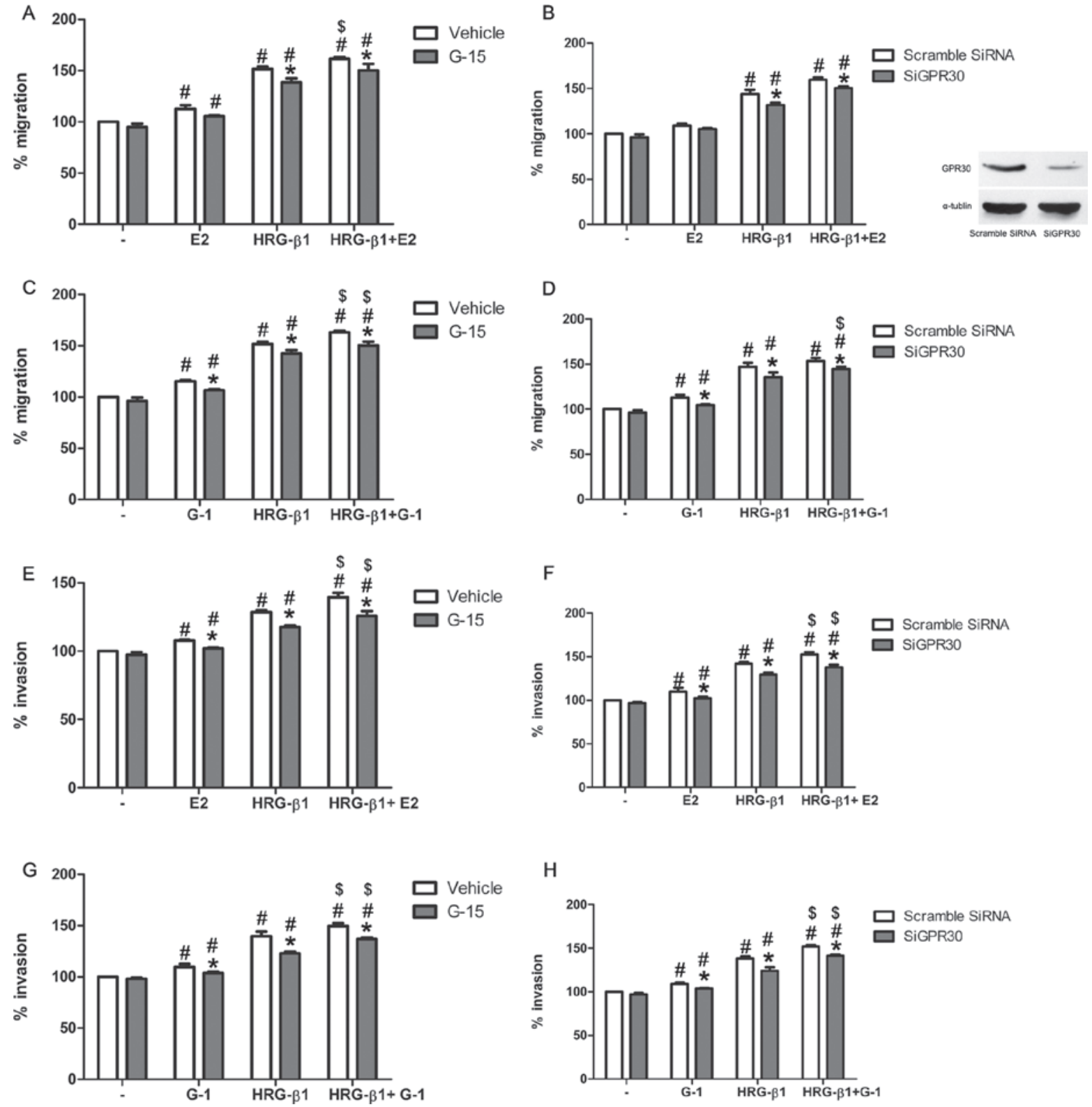

Figure 4. G protein-coupled receptor 30 (GPR30) is involved in the migration and invasion promoted by heregulin (HRG)- $\beta 1$ in MCF-7 cells. After being incubated with the indicated reagents for $48 \mathrm{~h}$, cells were counted under eight high-power fields per filter. Each data point is the mean \pm SD of three independent experiments performed in triplicate. (A, B, E and F) Migrations and invasion induced by $10 \mathrm{nM} 17-\beta$-estradiol (E2) alone or in combination with $20 \mathrm{ng} / \mathrm{ml}$ HRG- $\beta 1$ were abolished by $1 \mu \mathrm{M} \mathrm{G}-15$ or GPR30 silencing (siGPR30). * $<0.05$, for cells that received vehicle vs. G-15, or for cells that were transfected with scrambled siRNA vs. siGPR30. ${ }^{\#} \mathrm{P}<0.05$, for cells that received E2 and HRG- $\beta 1$ alone or a combination of E2 and HRG- $\beta 1$ vs. vehicle (-). ${ }^{\$} \mathrm{P}<0.05$, for cells that received HRG- $\beta 1$ alone vs. a combination of E2 and HRG- $\beta 1$. (C, D, G and H) Migrations and invasion induced by $1 \mu \mathrm{M}$ G- 1 alone or in combination with 20 ng/ ml HRG- $\beta 1$ were abolished by $1 \mu \mathrm{M} \mathrm{G}-15$ or GPR30 silencing (siGPR30). ${ }^{*} \mathrm{P}<0.05$, for cells that received vehicle vs. G-15, or for cells that were transfected with scrambled siRNA vs. siGPR30. ${ }^{\#} \mathrm{P}<0.05$, for cells that received G-1 and HRG- $\beta 1$ alone, or a combination of G-1 and HRG- $\beta 1$ vs. vehicle (-). ${ }^{\$} \mathrm{P}<0.05$, for cells that received HRG- $\beta 1$ alone vs. a combination of G-1 and HRG- $\beta 1$.

feedback loops are ubiquitous in cancer; therefore, whether the ErbB family regulates GPCRs is a pressing question. However, only a few reports on the upregulated expression of GPCRs by ErbB family members are available (42-45). The present study focused on the possible regulation of GPR30 by HRGs, another important group of ligands for ErbB receptors. As expected, HRG- $\beta 1$ upregulated GPR30 expression in the MCF-7-, T-47D- and BT-474-cultured breast cancer cell lines.

The binding of ligands results in the homo- and/or heterodimerization of ErbB receptors and activation of their intrinsic tyrosine kinase activity. Although ErbB2 is an orphan receptor with no known ligand, it is the preferred heterodimerization partner of other ErbB family members. On the other hand, ErbB3 requires dimerization with other ErbB members to activate its signaling due to an impaired intracellular tyrosine kinase domain (46). Moreover, ErbB3 constitutes a highaffinity HRG binding receptor only when co-expressed with ErbB2 (47); therefore, HRG binding to ErbB3 is stable and maintains the activation of the downstream signaling pathway (48). ErbB2-ErbB3 has been suggested to be the most potent heterodimer in cancer development $(49,50)$. In previous reports, the activation of the ErbB2-ERK signaling pathway has been 
shown to be involved in the regulation of GPCRs expression $(39,43,45,51,52)$. In our study, the ErbB2/neu tyrosine kinase inhibitor, AG825, as well as the MAPK inhibitor, PD98059, and the MEK1/2 inhibitor, U0126, decreased GPR30 expression in MCF-7 cells, which implies that ErbB2/3-MAPK/ ERK is the main signaling pathway related to the regulation of GPR30 by HRG- $\beta 1$.

Almost half of breast cancer patients with TAM treatment have clinical benefits. Nevertheless, a significant proportion of TAM-responsive breast cancer patients relapse with an antiestrogen-resistant phenotype, wherein GPR30 overexpression may be involved (53-55). Previous reports have demonstrated that cell models of acquired endocrine resistance have a high migratory capability (56-58), and those patients with acquired endocrine resistance also present with local and/or regional recurrences, frequently with distant metastases $(59,60)$. GPR30 expression is not only associated with cancer growth, but also with metastases development (61). In primary breast tumors (10), epithelial ovarian cancer (62) and endometrial cancer (7), tumors with higher GPR30 expression are more metastastic compared to GPR30-negative tumors. Likewise, aggressive cancer cell lines express high GPR30 levels, whereas their associated normal cell lines show little or no GPR30 expression $(63,64)$. On the other hand, aberrant expression and activation of the ErbB system (e.g., phosphorylated EGFR, ErbB2 and/ or ErbB3) and overexpressed ErbB ligands (e.g., TGF- $\alpha$ and amphiregulin) are linked to endocrine therapy resistance in both breast cancer cells and breast tumors (65-67). Previous studies have suggested that HRGs are sufficient for breast cancer initiation and progression by promoting metastasis and angiogenesis; even in the absence of estrogen stimulation and the independence of ErbB2 overexpression (21,22,32,67-69). The blockage of HRG expression suppresses the aggressive phenotype by inhibiting tumor growth and metastasis (32). It has been reported that common target genes relative to metastasis between GPR30 and HRG- $\beta 1$ exist, such as connective tissue growth factor (CTGF) (70), fibronectin (FN) (71), chemokine receptor type 4 (CXCR4) (72) and matrix metalloproteinase (MMP)-9 (73). Our results showed that E2 or G-1 boosted the migration and invasion induced by HRG- $\beta 1$ in MCF-7 cells. As mentioned above, GPR30 was regulated by HRG- $\beta 1$; therefore, all these results imply that GPR30 may be involved in the endocrine therapy resistance and tumor metastasis as a downstream molecule of HRG- $\beta 1$.

The recent clinical use of specific signal transduction inhibitors is one of the most promising therapeutic approaches in breast cancers. The MEK inhibitor, PD98059, and the PI3K inhibitor, LY294002, have both been shown to enhance the cytostatic effect of OH-TAM or fulvestrant in MVLN sensitive cells, and the inhibition of MAPK or PI3K/Akt pathways associated with endocrine therapy has been shown to be sufficient to reverse OH-TAM or fulvestrant resistance (74). In our study, the specific GPR30 antagonist, G-15, inhibited the migration and invasion induced by E2, HRG- $\beta 1$ alone or the combination of both. Our results imply that the therapy targeting GPR30 signaling may be a promising way to treat breast cancer.

In conclusion, HRG- $\beta 1$ upregulates GPR30 expression primarily through the ErbB2-ERK pathway. Considering that the stimulation of GPR30 transactivates EGFR signaling, HRG- $\beta 1$ induces a positive loop formation between the ErbB family and GPR30, EGF and TGF- $\alpha(11,12)$. Moreover, GPR30 boosts HRG- $\beta 1$-induced migration and invasion in MCF-7 cells after combination treatment with E2 or G-1, but decreases the proliferation. Therefore, our results suggest that the cooperation between GPR30 and HRG- $\beta 1$ may play an important role in endocrine therapy resistance and tumor recurrence. The present findings may facilitate the development of new strategies in controlling human breast cancer.

\section{Acknowledgements}

This study was supported by the National Natural Science Foundation of China (no. 30801341), and The Research Fund for the Doctoral Program of Higher Education, China (no. 200803351107).

\section{References}

1. Jordan VC and Brodie AM: Development and evolution of therapies targeted to the estrogen receptor for the treatment and prevention of breast cancer. Steroids 72: 7-25, 2007.

2. Holbro T and Hynes NE: ErbB receptors: directing key signaling networks throughout life. Annu Rev Pharmacol Toxicol 44: 195-217, 2004.

3. Marmor MD, Skaria KB and Yarden Y: Signal transduction and oncogenesis by ErbB/HER receptors. Int J Radiat Oncol Biol Phys 58: 903-913, 2004.

4. Liebmann C: EGF receptor activation by GPCRs: an universal pathway reveals different versions. Mol Cell Endocrinol 331: 222-231, 2011.

5. Maggiolini M, Vivacqua A, Fasanella G, et al: The G proteincoupled receptor GPR30 mediates c-fos up-regulation by 17 beta-estradiol and phytoestrogens in breast cancer cells. J Biol Chem 279: 27008-27016, 2004.

6. Filardo EJ and Thomas P: GPR30: a seven-transmembranespanning estrogen receptor that triggers EGF release. Trends Endocrinol Metab 16: 362-367, 2005.

7. He YY, Cai B, Yang YX, Liu XL and Wan XP: Estrogenic $\mathrm{G}$ protein-coupled receptor 30 signaling is involved in regulation of endometrial carcinoma by promoting proliferation, invasion potential, and interleukin-6 secretion via the MEK/ ERK mitogen-activated protein kinase pathway. Cancer Sci 100: 1051-1061, 2009.

8. Pandey DP, Lappano R, Albanito L, Madeo A, Maggiolini M and Picard D: Estrogenic GPR30 signalling induces proliferation and migration of breast cancer cells through CTGF. EMBO J 28: 523-532, 2009

9. Henic E, Noskova V, Hoyer-Hansen G, Hansson S and Casslen B: Estradiol attenuates EGF-induced rapid uPAR mobilization and cell migration via the $\mathrm{G}$-protein-coupled receptor 30 in ovarian cancer cells. Int J Gynecol Cancer 19: 214-222, 2009.

10. Filardo EJ, Graeber CT, Quinn JA, et al: Distribution of GPR30, a seven membrane-spanning estrogen receptor, in primary breast cancer and its association with clinicopathologic determinants of tumor progression. Clin Cancer Res 12: 6359-6366, 2006.

11. Vivacqua A, Lappano R and De Marco P, et al: $G$ protein-coupled receptor 30 expression is up-regulated by EGF and TGF alpha in estrogen receptor alpha-positive cancer cells. Mol Endocrinol 23: 1815-1826, 2009.

12. Albanito L, Sisci D, Aquila S, et al: Epidermal growth factor induces $\mathrm{G}$ protein-coupled receptor 30 expression in estrogen receptor-negative breast cancer cells. Endocrinology 149: 3799-3808, 2008

13. Ignatov A, Ignatov T, Weissenborn C, et al: G-protein-coupled estrogen receptor GPR30 and tamoxifen resistance in breast cancer. Breast Cancer Res Treat 128: 457-466, 2011.

14. Ignatov A, Ignatov T, Roessner A, Costa SD and Kalinski T: Role of GPR30 in the mechanisms of tamoxifen resistance in breast cancer MCF-7 cells. Breast Cancer Res Treat 123: 87-96, 2010.

15. Filardo EJ, Quinn JA, Bland KI and Frackelton AJ: Estrogen-induced activation of Erk-1 and Erk-2 requires the $\mathrm{G}$ protein-coupled receptor homolog, GPR30, and occurs via trans-activation of the epidermal growth factor receptor through release of HB-EGF. Mol Endocrinol 14: 1649-1660, 2000. 
16. Thomas P, Pang Y, Filardo EJ and Dong J: Identity of an estrogen membrane receptor coupled to a $G$ protein in human breast cancer cells. Endocrinology 146: 624-632, 2005.

17. Falls DL: Neuregulins: functions, forms, and signaling strategies. Exp Cell Res 284: 14-30, 2003.

18. Grunt TW, Saceda M, Martin MB, et al: Bidirectional interactions between the estrogen receptor and the cerbB-2 signaling pathways: heregulin inhibits estrogenic effects in breast cancer cells. Int J Cancer 63: 560-567, 1995.

19. Pietras RJ, Arboleda J, Reese DM, et al: HER-2 tyrosine kinase pathway targets estrogen receptor and promotes hormoneindependent growth in human breast cancer cells. Oncogene 10: 2435-2446, 1995.

20. Xue C, Liang F, Mahmood R, et al: ErbB3-dependent motility and intravasation in breast cancer metastasis. Cancer Res 66 : $1418-1426,2006$

21. de Alava E, Ocana A, Abad M, et al: Neuregulin expression modulates clinical response to trastuzumab in patients with metastatic breast cancer. J Clin Oncol 25: 2656-2663, 2007.

22. Cheng L, Zha Z, Lang B, Liu J and Yao X: Heregulin-beta1 promotes metastasis of breast cancer cell line SKBR3 through upregulation of Snail and induction of epithelial-mesenchymal transition. Cancer Lett 280: 50-60, 2009.

23. Filardo EJ, Quinn JA, Frackelton AJ and Bland KI: Estrogen action via the G protein-coupled receptor, GPR30: stimulation of adenylyl cyclase and cAMP-mediated attenuation of the epidermal growth factor receptor-to-MAPK signaling axis. Mol Endocrinol 16: 70-84, 2002.

24. Daly JM, Olayioye MA, Wong AM, et al: NDF/heregulininduced cell cycle changes and apoptosis in breast tumour cells: role of PI3 kinase and p38 MAP kinase pathways. Oncogene 18 3440-3451, 1999.

25. Ahola TM, Manninen T, Alkio N and Ylikomi T: G proteincoupled receptor 30 is critical for a progestin-induced growth inhibition in MCF-7 breast cancer cells. Endocrinology 143: 3376-3384, 2002.

26. Ahola TM, Purmonen S, Pennanen P, Zhuang YH, Tuohimaa P and Ylikomi T: Progestin upregulates G-protein-coupled receptor 30 in breast cancer cells. Eur J Biochem 269: 2485-2490, 2002.

27. Teng J, Wang ZY, Prossnitz ER and Bjorling DE: The G proteincoupled receptor GPR30 inhibits human urothelial cell proliferation. Endocrinology 149: 4024-4034, 2008

28. Chan QK, Lam HM, Ng CF, et al: Activation of GPR30 inhibits the growth of prostate cancer cells through sustained activation of Erk1/2, c-jun/c-fos-dependent upregulation of p21, and induction of G(2) cell-cycle arrest. Cell Death Differ 17: 1511-1523, 2010.

29. Ariazi EA, Brailoiu E, Yerrum S, et al: The G protein-coupled receptor GPR30 inhibits proliferation of estrogen receptorpositive breast cancer cells. Cancer Res 70: 1184-1194, 2010.

30. Madeo A and Maggiolini M: Nuclear alternate estrogen receptor GPR30 mediates 17beta-estradiol-induced gene expression and migration in breast cancer-associated fibroblasts. Cancer Res 70 6036-6046, 2010

31. Fraser SP, Ozerlat-Gunduz I, Onkal R, Diss JK, Latchman DS and Djamgoz MB: Estrogen and non-genomic upregulation of voltage-gated $\mathrm{Na}(+)$ channel activity in MDA-MB-231 human breast cancer cells: role in adhesion. J Cell Physiol 224: 527-539, 2010.

32. Tsai MS, Shamon-Taylor LA, Mehmi I, Tang CK and Lupu R: Blockage of heregulin expression inhibits tumorigenicity and metastasis of breast cancer. Oncogene 22: 761-768, 2003.

33. Daub H, Weiss FU, Wallasch $\mathrm{C}$ and Ullrich A: Role of transactivation of the EGF receptor in signalling by G-protein-coupled receptors. Nature 379: 557-560, 1996.

34. Prenzel N, Zwick E, Daub H, et al: EGF receptor transactivation by G-protein-coupled receptors requires metalloproteinase cleavage of proHB-EGF. Nature 402: 884-888, 1999.

35. Marone R, Hess D, Dankort D, Muller WJ, Hynes NE and Badache A: Memo mediates ErbB2-driven cell motility. Nat Cell Biol 6: 515-522, 2004

36. Hsieh M and Conti M: G-protein-coupled receptor signaling and the EGF network in endocrine systems. Trends Endocrino Metab 16: 320-326, 2005.

37. Arora P, Cuevas BD, Russo A, Johnson GL and Trejo J: Persistent transactivation of EGFR and ErbB2/HER2 by protease-activated receptor-1 promotes breast carcinoma cell invasion. Oncogene 27 4434-4445, 2008

38. Cotton $\mathrm{M}$ and Claing A: G protein-coupled receptors stimulation and the control of cell migration. Cell Signal 21: 1045-1053, 2009.
39. Ratchford AM, Baker OJ, Camden JM, et al: P2Y2 nucleotide receptors mediate metalloprotease-dependent phosphorylation of epidermal growth factor receptor and ErbB3 in human salivary gland cells. J Biol Chem 285: 7545-7555, 2010.

40. Sukocheva O, Wadham C, Holmes A, et al: Estrogen transactivates EGFR via the sphingosine 1-phosphate receptor Edg-3: the role of sphingosine kinase-1. J Cell Biol 173: 301-310, 2006.

41. Schafer B, Gschwind A and Ullrich A: Multiple G-proteincoupled receptor signals converge on the epidermal growth factor receptor to promote migration and invasion. Oncogene 23: 991-999, 2004

42. Yeh CK, Hymer TK, Sousa AL, Zhang BX, Lifschitz MD and Katz MS: Epidermal growth factor upregulates beta-adrenergic receptor signaling in a human salivary cell line. Am J Physiol Cell Physiol 284: C1164-C1175, 2003.

43. Koumbadinga GA, Petitclerc E, Bouthillier J, Adam A and Marceau F: Receptor tyrosine kinases as mediators of injuryinduced bradykinin B1 receptor expression in rabbit aortic smooth muscle. Eur J Pharmacol 606: 233-239, 2009.

44. Li YM, Pan Y, Wei Y, et al: Upregulation of CXCR4 is essential for HER2-mediated tumor metastasis. Cancer Cell 6: 459-469, 2004.

45. Shi M, Liu D, Duan H, et al: The beta2-adrenergic receptor and Her2 comprise a positive feedback loop in human breast cancer cells. Breast Cancer Res Treat 125: 351-362, 2011.

46. Breuleux M: Role of heregulin in human cancer. Cell Mol Life Sci 64: 2358-2377, 2007.

47. Sliwkowski MX, Schaefer G, Akita RW, et al: Coexpression of erbB2 and erbB3 proteins reconstitutes a high affinity receptor for heregulin. J Biol Chem 269: 14661-14665, 1994.

48. Kani K, Park E and Landgraf R: The extracellular domains of ErbB3 retain high ligand binding affinity at endosome $\mathrm{pH}$ and in the locked conformation. Biochemistry 44: 15842-15857, 2005.

49. Pinkas-Kramarski R, Shelly M, Guarino BC, et al: ErbB tyrosine kinases and the two neuregulin families constitute a ligandreceptor network. Mol Cell Biol 18: 6090-6101, 1998.

50. Pinkas-Kramarski R, Lenferink AE, Bacus SS, et al: The oncogenic ErbB-2/ErbB-3 heterodimer is a surrogate receptor of the epidermal growth factor and betacellulin. Oncogene 16: 1249-1258, 1998.

51. Cabioglu N, Summy J, Miller C, et al: CXCL-12/stromal cellderived factor-1alpha transactivates HER2-neu in breast cancer cells by a novel pathway involving Src kinase activation. Cancer Res 65: 6493-6497, 2005.

52. Chinni SR, Yamamoto H, Dong Z, Sabbota A, Bonfil RD and Cher ML: CXCL12/CXCR4 transactivates HER2 in lipid rafts of prostate cancer cells and promotes growth of metastatic deposits in bone. Mol Cancer Res 6: 446-457, 2008.

53. Gottardis MM, Robinson SP, Satyaswaroop PG and Jordan VC: Contrasting actions of tamoxifen on endometrial and breast tumor growth in the athymic mouse. Cancer Res 48: 812-815, 1988.

54. Gottardis MM and Jordan VC: Development of tamoxifen-stimulated growth of MCF-7 tumors in athymic mice after long-term antiestrogen administration. Cancer Res 48: 5183-5187, 1988.

55. Craig JV, Lewis-Wambi J, Kim H, et al: Exploiting the apoptotic actions of oestrogen to reverse antihormonal drug resistance in oestrogen receptor positive breast cancer patients. Breast 16 (Suppl 2): 105-113, 2007.

56. Hiscox S, Morgan L, Green TP, Barrow D, Gee J and Nicholson RI: Elevated Src activity promotes cellular invasion and motility in tamoxifen resistant breast cancer cells. Breast Cancer Res Treat 97: 263-274, 2006.

57. Al SS, Sharaf LH and Luqmani YA: Signalling pathways involved in endocrine resistance in breast cancer and associations with epithelial to mesenchymal transition (Review). Int J Oncol 38: 1197-1217, 2011.

58. Hayes E, Nicholson RI and Hiscox S: Acquired endocrine resistance in breast cancer: implications for tumour metastasis. Front Biosci 16: 838-848, 2011.

59. Nicholson RI, Gee JM, Knowlden J, et al: The biology of antihormone failure in breast cancer. Breast Cancer Res Treat 80 (Suppl 1): 29-35, 2003

60. Nicolini A, Giardino R, Carpi A, et al: Metastatic breast cancer: an updating. Biomed Pharmacother 60: 548-556, 2006.

61. Filardo EJ, Quinn JA and Sabo E: Association of the membrane estrogen receptor, GPR30, with breast tumor metastasis and transactivation of the epidermal growth factor receptor. Steroids 73: 870-873, 2008

62. Smith HO, Arias-Pulido H, Kuo DY, et al: GPR30 predicts poor survival for ovarian cancer. Gynecol Oncol 114: 465-471, 2009. 
63. Revankar CM, Cimino DF, Sklar LA, Arterburn JB and Prossnitz ER: A transmembrane intracellular estrogen receptor mediates rapid cell signaling. Science 307: 1625-1630, 2005.

64. Bologa CG, Revankar CM, Young SM, et al: Virtual and biomolecular screening converge on a selective agonist for GPR30. Nat Chem Biol 2: 207-212, 2006.

65. Kurokawa H, Lenferink AE, Simpson JF, et al: Inhibition of HER2/ neu (erbB-2) and mitogen-activated protein kinases enhances tamoxifen action against HER2-overexpressing, tamoxifenresistant breast cancer cells. Cancer Res 60: 5887-5894, 2000.

66. Britton DJ,Hutcheson IR, Knowlden JM, et al: Bidirectional cross talk between ERalpha and EGFR signalling pathways regulates tamoxifen-resistant growth. Breast Cancer Res Treat 96: 131-146, 2006.

67. Atlas E, Cardillo M, Mehmi I, Zahedkargaran H, Tang C and Lupu R: Heregulin is sufficient for the promotion of tumorigenicity and metastasis of breast cancer cells in vivo. Mol Cancer Res 1: 165-175, 2003.

68. Kumar R and Yarmand-Bagheri R: The role of HER2 in angiogenesis. Semin Oncol 28: 27-32, 2001.
69. Hijazi MM, Thompson EW, Tang C, et al: Heregulin regulates the actin cytoskeleton and promotes invasive properties in breast cancer cell lines. Int J Oncol 17: 629-641, 2000.

70. Amin DN, Tuck D and Stern DF: Neuregulin-regulated gene expression in mammary carcinoma cells. Exp Cell Res 309: 12-23, 2005.

71. Vadlamudi RK, Adam L, Nguyen D, Santos M and Kumar R: Differential regulation of components of the focal adhesion complex by heregulin: role of phosphatase SHP-2. J Cell Physiol 190: 189-199, 2002.

72. Hernandez L, Smirnova T, Kedrin D, et al: The EGF/CSF-1 paracrine invasion loop can be triggered by heregulin betal and CXCL12. Cancer Res 69: 3221-3227, 2009.

73. Yao J, Xiong S, Klos K, et al: Multiple signaling pathways involved in activation of matrix metalloproteinase-9 (MMP-9) by heregulin-beta1 in human breast cancer cells. Oncogene 20 : 8066-8074, 2001.

74. Ghayad SE, Vendrell JA, Ben LS, Dumontet C, Bieche I and Cohen PA: Endocrine resistance associated with activated ErbB system in breast cancer cells is reversed by inhibiting MAPK or PI3K/Akt signaling pathways. Int J Cancer 126: 545-562, 2010. 